\title{
Gastrointestinal Complications of Schistosomiasis
}

\author{
Theodore W. Schafer, $M D^{*}$ and Braden R. Hale, MD, MPH
}

\author{
Address \\ *Clinical Investigation Department (KCA), Naval Medical Center, \\ San Diego, 34800 Bob Wilson Drive, Suite 5, San Diego, \\ CA $92134-1005$, USA. \\ Current Gastroenterology Reports 200I, 3:293-303 \\ Current Science Inc. ISSN 1522-8037 \\ Copyright $@ 2001$ by Current Science Inc.
}

Schistosomiasis is an important disease in many parts of the world and has affected the course of human history many times over. The parasitic infection is acquired during contact with infected water. A chronic inflammatory response to schistosome eggs, mediated by both cellular and humoral mechanisms, is the root of the pathology seen in schistosomiasis. Hepatosplenic disease results in intrahepatic presinusoidal portal hypertension. The resultant esophageal and gastric varices are an important cause of morbidity and mortality. Standard treatment guidelines for managing varices can be applied to patients with schistosomiasis. Coinfection with viral hepatitis results in liver disease that progresses more rapidly and is more difficult to treat. Intestinal schistosomiasis may be confused with other disease states and can be an important cause of morbidity, especially in heavily infected patients. Diagnosis relies on demonstration of schistosome eggs in feces or tissue. Praziquantel is the treatment of choice. The development of a vaccine for schistosomiasis is an important goal in the attempt to control this disease.

\section{Introduction}

Schistosomiasis is a common disease of the tropical world, affecting an estimated 200 million or more individuals and causing an estimated 500,000 deaths every year. The disease has been described in humans for several millennia. Its current increased prevalence in many areas has numerous causes, including increased irrigation in areas with inadequate waste disposal and breakdown in public health infrastructure. The most common significant clinical effects of infection of two of the three important species infecting humans are intestinal and hepatic manifestations, which can result in serious illness or death.

\section{History}

Schistosome eggs have been identified in both Egyptian and Chinese mummies from antiquity [1]. The presence of hema- turia, presumably as a result of Schistosoma hematobium infection, is noted repeatedly in Egyptian pharaonic writing [2], and schistosomiasis has been noted historically in other Middle Eastern cultures and in China. The disease affected many of Napoleon's troops during his campaign to conquer Egypt..

The causative organism was not identified until 1851 by Bilharz, who discovered the trematode during an autopsy at the Kasr-El-Ani Hospital in Cairo, Egypt. Although Manson speculated that the urinary and intestinal forms of schistosomiasis might be caused by two distinct species, it was not until 1907 that $S$. mansoni was identified as a separate species. In Japan, the illness of acute schistosomiasis, Katayama fever, was described in detail for the first time in 1847, and the causative pathogen, $S$. japonicum, was identified in 1904 by Katsurada.

The schistosome had a more recent impact on the history of Taiwan $[3,4]$. The People's Republic of China (PRC) had assembled an invasion force in 1950 to overcome the recently established nationalist Chinese in Taiwan. Because amphibious landing craft were not in adequate supply, most PRC soldiers needed to be able to swim during the anticipated invasion. Swimming instruction was given in canals in Chekiang and Fukien, areas endemic for S. japonicum. An estimated 30,000 to 50,000 cases of Katayama fever developed among the PRC forces, aborting the invasion plans. By the time the invasion force had regained collective strength, the Korean War and the presence of the US Seventh Fleet deterred further invasion plans. Because of these circumstances, the schistosome has been credited with "saving" Taiwan.

\section{Epidemiology}

Three main Schistosoma species cause disease in humans: S. mansoni, S. haematobium, and S. japonicum (Table 1). Additionally, a number of other species that are less widely distributed can infect humans. Schistosomiasis from all species is confined to tropical areas between the latitudes of $36^{\circ}$ North and South. The distribution of the parasite is absolutely dependent on the distribution of the intermediate snail host, which lives in muddy banks of slow-moving fresh water sources. People may become infected when their skin is exposed to infested fresh water. However, the risk of infection may vary with the season, time of day, nature of exposure, and microclimate, as well as host factors. Therefore, the distribution of disease tends to be focal and irregular. Even 


\begin{tabular}{|c|c|c|c|c|c|}
\hline & S. mansoni & S. haematobium & S. japonicum & S. intercalatum & S. mekongi \\
\hline Distribution & $\begin{array}{l}\text { Africa, Middle East, } \\
\text { Caribbean, South } \\
\text { America }\end{array}$ & $\begin{array}{l}\text { Africa, Middle East, } \\
\text { India }\end{array}$ & $\begin{array}{l}\text { China, Philippines, } \\
\text { Southeast Asia }\end{array}$ & Africa & $\begin{array}{l}\text { Cambodia, Laos } \\
\text { (Mekong River } \\
\text { Basin) }\end{array}$ \\
\hline $\begin{array}{l}\text { Intermediate } \\
\text { snail host }\end{array}$ & Biomphalaria & Bulinus & Oncomelania & Bulinus & Neotricula \\
\hline Reservoir & $\begin{array}{l}\text { Humans } \\
\text { (main reservoir), } \\
\text { rodents, baboons, } \\
\text { insectivores }\end{array}$ & Humans & $\begin{array}{l}\text { Humans, water } \\
\text { buffalo, cattle, } \\
\text { dogs, cats, pigs, } \\
\text { and many others }\end{array}$ & Humans, rodents & Humans, dogs \\
\hline Egg morphology & $\begin{array}{l}\text { Oval egg with } \\
\text { lateral spine }\end{array}$ & $\begin{array}{l}\text { Oval egg with } \\
\text { terminal spine }\end{array}$ & $\begin{array}{l}\text { Round/oval egg } \\
\text { with small } \\
\text { lateral spine }\end{array}$ & $\begin{array}{l}\text { Oval egg (Ziehl- } \\
\text { Nielsen positive) } \\
\text { with terminal } \\
\text { spine }\end{array}$ & $\begin{array}{l}\text { Round/oval smaller } \\
\text { egg with small } \\
\text { lateral spine }\end{array}$ \\
\hline $\begin{array}{l}\text { Disease } \\
\text { predilection }\end{array}$ & Intestinal and liver & Urinary tract & Intestinal and liver & Intestinal & Intestinal and liver \\
\hline
\end{tabular}

within an endemic area, the burden of disease is not uniform. Children tend to be exposed more intensely to infection because of recreational water activities and are likely to expose a greater surface area to contaminated water. Peak intensity of infection is between the ages of 8 and 12 years in highly endemic areas and somewhat later in areas that are less endemic [5]. Adults tend to have lower prevalence and burden of disease. Epidemiologic studies, most notably chemotherapy/reacquisition studies, also point to an agerelated acquired immunity to the parasite [6].

Disease within an infected area is related to the level of exposure, with more intense exposure related to greater prevalence of disease. Subtle signs of infection, such as anemia, fatigue, diarrhea, or hematuria, may be fairly common in a community, whereas severe illness may be present in as few as $10 \%$ of individuals in even the most heavily infected areas.

Humans are the only maintenance hosts for $S$. haematobium, and in most cases the important host for S. mansoni, although rodents and primates play a significant role in sustaining the life cycle in some areas. A number of mammals, including water buffalo, are natural reservoirs for $S$. japonicum.

Schistosomiasis is considered largely a disease of poor rural areas, and control efforts have not yet managed to show an impact in some of the most highly infected areas. The disease is spreading in some urban areas as well. Causes include irrigation efforts (which not only create new habitats for the snail intermediate host but also provide more water contact for residents), breakdown of public health infrastructure, and mass migration of infected populations to previously uninfected areas [7].

\section{Natural History}

The Schistosoma parasite requires both an intermediate host (snail) and a definitive host (human) (Fig. 1). When an egg passes into fresh water, a miracidium hatches. The miracidium is ciliated, and it searches for a suitable snail intermediate host. If the miracidium is successful in infecting a snail, the next stage of the organism develops (mother sporocyst). From germinal cells of this mother sporocyst grow daughter sporocysts, which in turn produce cercariae. The cercariae emerge directly from the snail into the water and swim about in hope of locating a suitable host. The cercariae cannot survive for more than 72 hours after emerging from the snail. If the cercaria locates a host, it attaches and penetrates the intact skin, shedding its tail in the process. The organism, now called a schistosomula, travels in the venous bloodstream to the lungs, where it squeezes through the pulmonary capillaries to enter the arterial bloodstream. After mating permanently, the worm pair eventually settles in its location of choice.

The preferred anatomic location varies by species and can change over the life of the worm: $S$. mansoni prefers the inferior mesenteric venules; $S$. japonicum the superior and inferior mesenteric venules; $S$. mekongi the superior mesenteric venules; and $S$. hematobium the plexi of the urinary bladder (Table 1). The eggs are deposited into the vascular lumen. Using irritative and digestive compounds, about half of the ova are able to penetrate through the wall of the blood vessel directly into the bowel or bladder. The rest of the eggs are carried to the liver (S. mansoni and S. japonicum) or the lungs ( $S$. haematobium and others in advanced disease), where they are filtered from the circulation. The rates of egg deposition vary by species: S. japonicum, 500 to $3500 / d$; S. mansoni, 100 to 300/d; and S. haematobium, 20 to $200 / d$.

S. mekongi, S. malayi, S. intercalatum, and other species are also important pathogens, although they are limited in geographic distribution. The presentation of S. malayi and $S$. mekongi, which may cause severe disease, should be considered clinically analogous to that of $S$. japonicum 


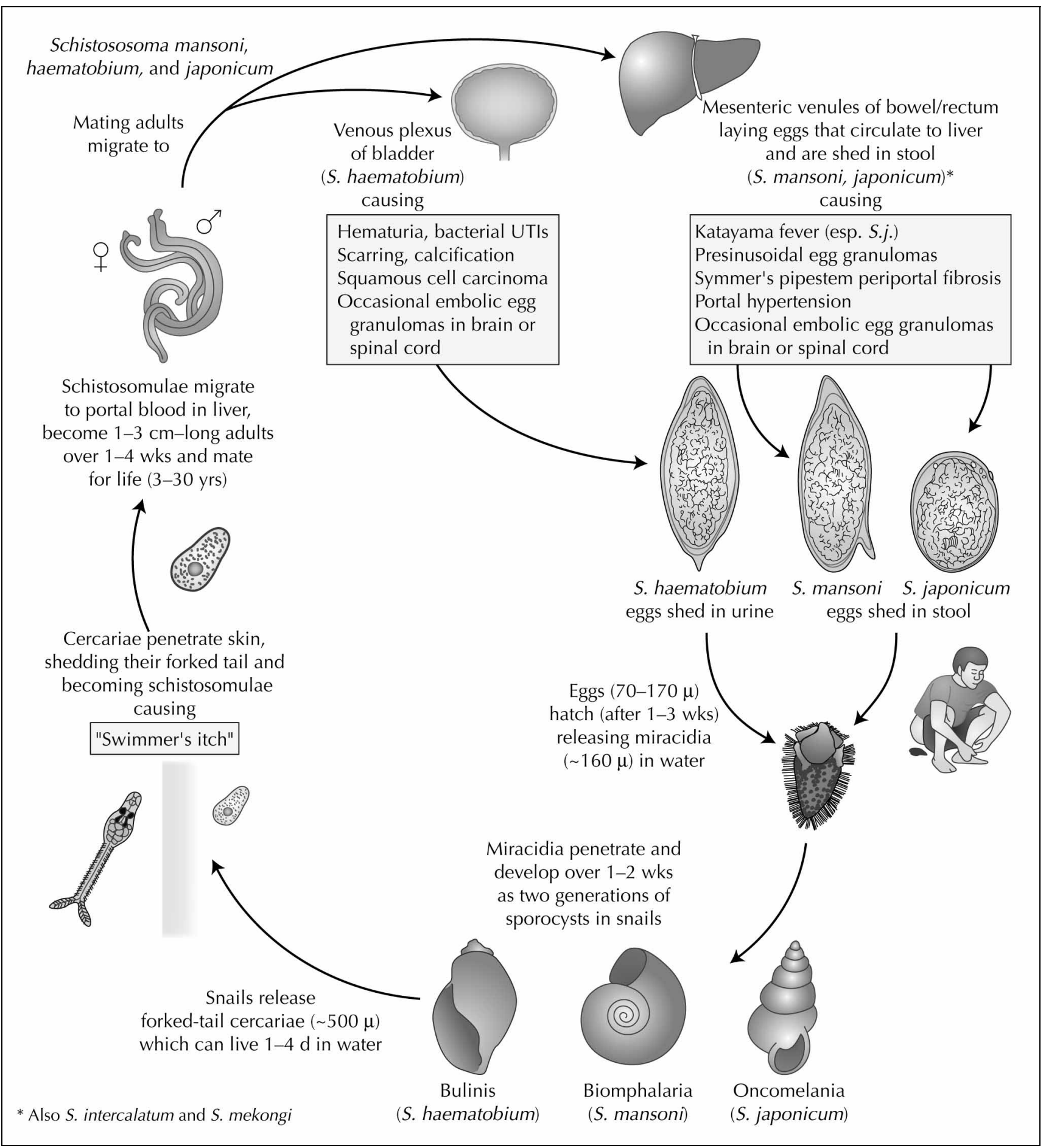

Figure 1. Life cycle of the important human Schistosoma species. From Melvin et al. [82].

infection. S. intercalatum infection causes mostly intestinal symptoms such as rectal bleeding and diarrhea.

\section{Pathology/Pathogenesis}

The disease in schistosomiasis is a result of host response to the worm at some point in its life cycle. The host may develop a response during the skin penetration phase, the pulmonary migration phase, the initial egg deposition, or the chronic egg deposition. The latter instance is responsible for virtually all the significant morbidity and mortality of schistosomiasis.

The exuberant inflammatory response to the schistosome eggs results in lesions composed of $\mathrm{T}$ cells and other inflammatory cells. These lesions progress to form granulomas made of T- and B-lymphocytes and large monocytes. Ultimately, non-caseating granulomas form $[8,9]$. 
The initial response by the host appears to require $\mathrm{CD}^{4+}$ cells; animals depleted of these cells are not able to form granulomas [10]. The CD4 response is initially a T-helper cell type 1 (Th1) response, with production of interleukin12 (IL-12), interferon-gamma (IFN- $\gamma$ ), and IL-2 [11•]. The immune response may shift to a T-helper cell type 2 (Th2) response with production of transforming growth factorbeta (TGF- $\beta$ ) and IL-10, both of which appear to be beneficial in limiting disease. The Th2-type response has been noted in humans to be more closely associated with the "intestinal" form of S. mansoni, whereas the Th1-type response has been associated with the more debilitating "hepatosplenic" form of disease [11•]. Similarly, mice that are unable to mount a TGF- $\beta$ response are noted to develop extensive hepatic fibrosis [12].

The phenomenon of immunomodulation, which manifests as a reduction in the size and change in composition of the granulomas coincident with gross changes such as reduction in portal vein inflammation and vascular obstruction, may be a result of the transition from a Th1 to a Th2 response [11 $\bullet$ ]. In addition, a segment of the human genome, 5q31-33, has been associated with

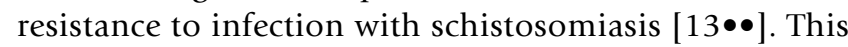
chromosome segment seems to be associated with the Th2 immune response.

Humoral responses are also important in pathogenesis. Antibodies to soluble egg antigen (SEA) are vigorous in acute infection, whereas, in chronic infection, those with lower antibody responses to SEA have less pathology [14]. Elevated serum IgE levels also seem to protect against reinfection in endemic areas [15]. Furthermore, sera from chronically infected humans slows egg maturation and modulates granuloma development in mice [16]. TGF- $\beta$ expression in mice is also associated with degree of fibrosis [17].

\section{Clinical Syndromes}

Schistosomiasis has many pulmonary, neurologic, renal, genital, and other manifestations that are beyond the scope of this review. One should note, however, that various Salmonella species and other enteric bacteria can cause a chronic bacteremia in individuals with schistosomiasis and result in an indolent presentation. A number of common clinical syndromes are described in the following sections.

\section{Cercarial dermatitis}

Entry of cercariae into the skin can result in a typical eruption known as "swimmer's itch." This dermatitis can be caused by human or non-human cercariae and has little intrinsic clinical significance. However, the history of such a rash provides important information to clinicians attempting to make a diagnosis of schistosomiasis in a returning traveler. The dermatitis is self-limited and generally responds to topical steroids.

\section{Katayama fever}

The syndrome of acute schistosomiasis, known as Katayama fever, occurs in previously uninfected individuals. Katayama fever is named for a district in Japan, which harbored a high prevalence for $S$. japonicum. Visitors from other parts of Japan often became ill, sometimes severely. Katayama fever is now known to occur in S. japonicum, S. mansoni, and S. haematobium infections and occurs most commonly in those with heavy exposure, although it may occur in lightly infected people as well. Fever, headache, myalgias, diarrhea and loss of appetite characterize the illness. Marked eosinophilia is common. Katayama fever is usually self-limited, lasting 2 to 3 weeks. Rarely, the illness is life threatening.

\section{Hepatosplenic schistosomiasis}

Most of the chronic pathology from schistosomiasis results from fibrosis. The most important cause of chronic morbidity from schistosomiasis is portal hypertension, which occurs in $5 \%$ to $10 \%$ of patients [18]. Most fibrosis occurs around the intrahepatic portal veins and results from excess deposition of type I and type III collagen. The host immune response to the eggs, as described earlier, results in granulomatous fibrosis surrounding the intrahepatic portal vasculature. Eventually, the scarring causes fibrotic restriction of portal flow and intrahepatic presinusoidal portal hypertension. Fibrosis in early schistosomiasis is largely reversible, whereas that of chronic disease may be permanent. No significant impact on end-stage fibrosis is noted with eradication of the parasite.

Symmers [19] first described the gross appearance of schistosomal periportal fibrosis in 1904. He observed that "the cut surface of the liver looks as if a number of white clay-pipe stems had been thrust at various angles through the organ." This pattern of periportal fibrosis is now known as Symmers' pipestem fibrosis. Computed tomography (CT) may show the classic "turtle-back" pattern of scar distribution because of the resemblance to the scutes on the dorsal shell of turtles (Fig. 2).

Ultrasound has become important for staging and monitoring of liver disease in schistosomiasis. Numerous ultrasound staging systems have been developed to evaluate the extent and severity of periportal fibrosis. The Cairo classification is the most widely used [20]. Recent modifications to this scheme have been proposed to broaden applicability and improve reliability, especially in children, and to allow for differences in available ultrasound equipment [21 •]. Correlation between ultrasound and histologic findings is satisfactory unless concomitant cirrhosis from other causes is present [22]. Recently, serum markers associated with fibrosis have been evaluated for noninvasive monitoring of liver fibrosis activity [23].

Schistosomal periportal hepatic fibrosis alone does not result in hepatocellular dysfunction. A compensatory increase in hepatic artery blood flow preserves oxygen delivery and thereby minimizes direct hepatocyte damage. 

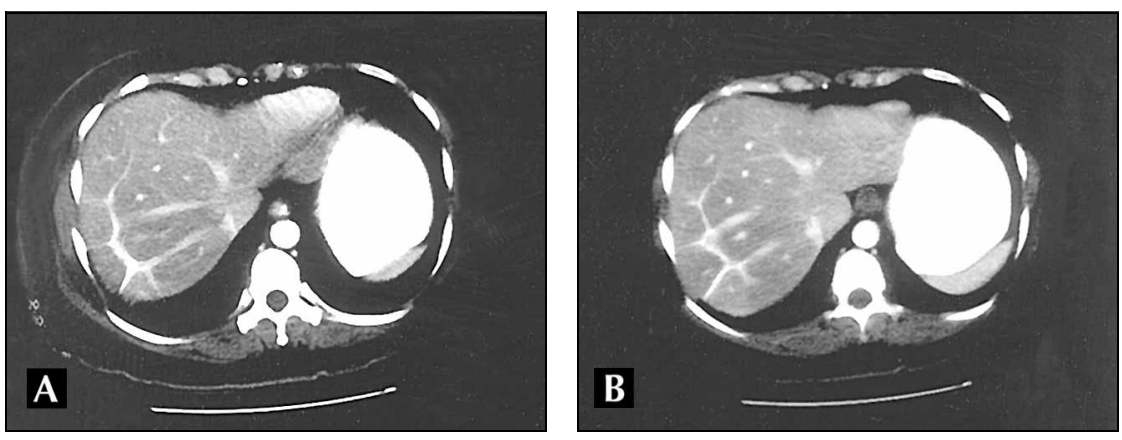

Figure 2. CT scan from a patient with hepatic schistosomiasis showing the "turtle-back" distribution of periportal fibrosis.
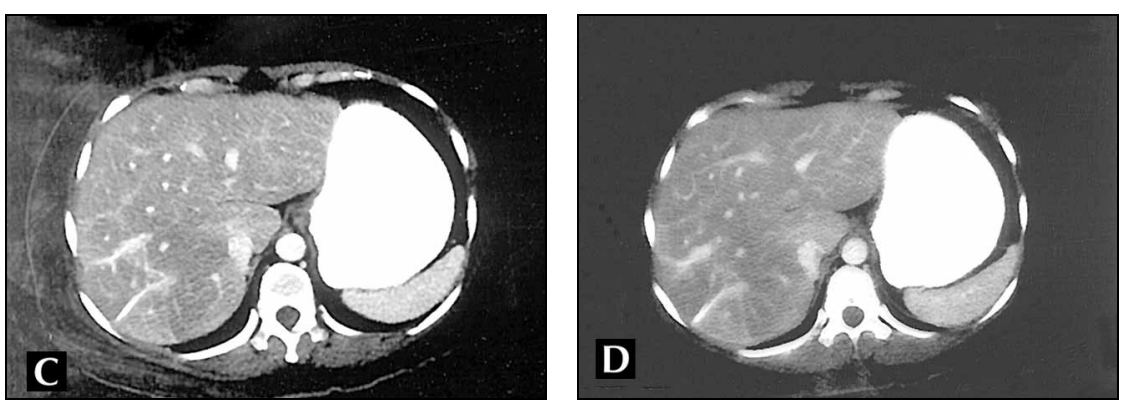

Thus, in the absence of other disease states leading to cirrhosis there are no peripheral stigmata of chronic liver disease. Palmar erythema, gynecomastia, testicular atrophy, spider angioma, and jaundice do not develop.

Patients suffering from hepatosplenic schistosomiasis typically have normal serum aminotransferase levels with mild increases in alkaline phosphatase and serum IgG [24]. Evidence of hypersplenism, especially in the form of thrombocytopenia, is common [18].

Physical examination classically reveals left-lobe hepatomegaly and moderate splenomegaly. The right hepatic lobe is often atrophic. Late disease is manifested as hepatic atrophy and marked splenomegaly with substantial ascites and peripheral muscle wasting.

\section{Varices}

Hemodynamic studies of schistosomiasis patients demonstrate hyperdynamic systemic and splanchnic blood flow [25]. Furthermore, patients who develop portal hypertension frequently develop impressive portosystemic collateral blood flow, most often in the form of esophageal and/or gastric varices.

Esophageal varices and subsequent hemorrhage are the most common serious complications of schistosomeinduced portal hypertension [26]. Although these patients tend to fare better than cirrhotic patients with variceal bleeding, mortality is still high.

Bleeding prophylaxis with nonspecific beta blockers has been studied in schistosomiasis patients with varices. Based on a classic study and other investigations of non-schistosomiasis patients, these drugs are recommended for prevention of first variceal bleed $[27,28]$. Furthermore, when possible, these agents should be used as adjunctive treatment for patients who have already had an index bleed.
Band ligation is widely recognized as the treatment of choice and standard of care for elective treatment of bleeding esophageal varices. The applicability of this standard to the discrete subset of patients with schistosomal portal hypertension can be questioned because most studies of variceal bleeding are done in regions where schistosomiasis is not an important cause of esophageal varices. However, based on small studies of patients with either "pure" schistosomal intrahepatic presinusoidal portal hypertension or those with mixed schistosomiasis and cirrhosis (mostly viral), treatment for variceal bleeding seems to be applicable to patients with schistosomiasis. Specifically, endoscopic band ligation [29] and endoscopic sclerotherapy [30] achieve good rates of hemostasis with lower complication rates than in patients with other causes of portal hypertension. Relative efficacy is consistent with larger studies in other groups.

A subset of patients with esophageal varices develops gastric fundal varices. Band ligation and injection sclerotherapy are less effective for bleeding from gastric varices caused by cirrhosis. However, results from one small study $(n=20)$ of injection sclerotherapy suggest that this modality is an effective bridge to surgery for bleeding gastric varices in patients with schistosomiasis [31].

A study of cyanoacrylate injection in 80 schistosomiasis patients with bleeding esophageal and gastric varices produced a short-term hemostasis rate of $95 \%$, with one treatment-related death. Overall mortality was 7.5\% [32•]. This method uses $N$-butyl-cyanoacrylate mixed with iodized oil. The mixture is injected directly into the lumen of the varix, where it polymerizes and hardens almost instantly, thus occluding and sclerosing the vessel. Cyanoacrylate injection for hemostasis in variceal bleeding is not approved for use in the United States. 
Surgical treatment for control of variceal bleeding includes various methods of portosystemic shunting such as the distal splenorenal shunt. Devascularization procedures are another surgical option. The more common of these-the gastroesophageal decongestion and splenectomy (GEDS) - is a manual ligation of collateral flow with splenectomy [33]. Generally, surgical methods have the advantage of long-term reduction in recurrent bleeding with minimal long-term morbidity $[34,35]$.

The transjugular intrahepatic portosystemic shunt (TIPS) is one method that appears to be less effective in patients with schistosomiasis than in other patients with portal hypertension [36]. Extrapolating from studies of non-schistosomiasis patients, stent patency diminishes over time [37]. Higher rates of stent occlusion in schistosomiasis patients can be expected because the underlying hepatic parenchyma is normal. These patients therefore have greater longevity along with normal foreign body and healing responses.

Aside from TIPS, studies of treatments for non-schistosomal variceal hemorrhage can be extrapolated to patients with schistosomiasis. From a therapeutic point of view, it seems clear that the cause of the variceal bleeding, whether from schistosomal portal hypertension or another etiology, is not important. Practitioners can be reassured that interventions to treat variceal bleeding in the setting of schistosomiasis are likely to be at least as successful (if not more so) as they would be in patients with other causes of portal hypertension. These results are not unexpected, given the normal hepatic function in schistosomiasis. Therefore, current guidelines for managing the serious complication of portal hypertensive bleeding are appropriate in the setting of schistosomiasis [38••]. Of course, eradication of the parasite is also crucial.

\section{Comorbid liver disease and schistosomiasis}

Hepatitis C virus (HCV) infection is hyperendemic in Egypt, where schistosomiasis is also very common. HCV prevalence is reported at $10 \%$ to $20 \%$ in Egyptian volunteer blood donors [39]. The rate of HCV seroprevalence exceeds $50 \%$ in the subgroup of patients aged 40 to 67 years. These authors also found a rate of antischistosomal antibodies of $89 \%$ in the same age group [40]. Hepatitis B virus (HBV) infection is also very common in Egypt, approaching a prevalence of $60 \%$ in some age groups $[40,41]$. Overall seroprevalence of HBV in Egypt of about $40 \%$ is reported, demonstrating the importance of this infection [42].

The situation in Egypt is unique, with an extremely high rate of $\mathrm{HCV}$ infection directly related to well-intentioned schistosome control efforts. Beginning in the 1920s and continuing until the mid-1980s, massive efforts were made to control schistosomiasis using parenteral drugs such as potassium antimony tartrate. The re-use of injection equipment during the antischistosome campaigns directly spread HCV and possibly HBV [43••]. In other countries where schistosomiasis is common, such as Brazil, the rates of HCV are substantially lower: between $1.2 \%$ and $4.6 \%$ [44]. Thus, the Egyptian population provides an unfortunate opportunity to evaluate the impact of combined infection with schistosomiasis and chronic viral hepatitis.

The implications of coinfection with schistosomiasis and chronic viral hepatitis are important. Patients with schistosomiasis have a relative risk of 5.22 (95\% CI 2.93 to 9.31) for developing hepatocellular carcinoma (HCC) [45•]. HCV and HBV are also substantial risk factors for the subsequent development of HCC. Thus, the combined effects of schistosomiasis and chronic viral hepatitis, with significant overlap in worldwide distribution, are relevant both to individual patients and to public health.

In a small study, Kamal et al. [46•] found that patients coinfected with schistosomiasis had higher HCV viral titers, higher histologic activity index scores, and less likelihood of achieving sustained response to anti-HCV therapy when compared with patients who had HCV alone. They propose that the mechanism is the known effect of schistosomiasis in downregulating the Th1 response [47] and conclude that coinfection with schistosomiasis results in HCV that progresses faster and is more resistant to treatment than in HCV alone. Whether combination therapy with IFN- $\alpha 2 b$ and ribavirin will be successful in this group of patients remains to be seen.

No recommendations about treatment in coinfected individuals have appeared in published reports. However, given that schistosomiasis results in poorer response to antiviral therapy, it seems reasonable to treat schistosomiasis first in coinfected patients before embarking on antiviral therapy. The importance of preventing reinfection with schistosomiasis, especially during treatment for viral hepatitis, should be obvious. Furthermore, vaccination against HBV in nonimmune individuals is vital in controlling this risk factor.

\section{Intestinal schistosomiasis}

The preferred home of S. mansoni, S. japonicum, and the less commonly encountered $S$. intercalatum and S. mekongi, is the venous splanchnic vasculature. As noted earlier, the flukes will selectively inhabit certain vessels and their branches (Table 1). As the adult worms move through the vessels, the female lays numerous eggs, again the root of pathology in this disease. The eggs produce a local inflammatory response, which can be massive. To complete the life cycle, some of the eggs eventually penetrate into the lumen of the bowel, where they are shed in the feces. Some of the eggs, however, remain trapped within intestinal tissue and cause intestinal pathology (Fig. 3).

As expected, there is a wide spectrum of presentation in intestinal schistosomiasis relative to location of egg deposition, intensity of infection, and host factors in response to infection. Acute symptoms are often nonspecific and can include bloody mucoid diarrhea, tenesmus, abdominal pain, bowel obstruction, fever, and weight loss [48]. The differential diagnosis is broad (Table 2).

Chronic infection leads to granulomatous polyp formation, which can be extensive [49]. Large, mass-like 


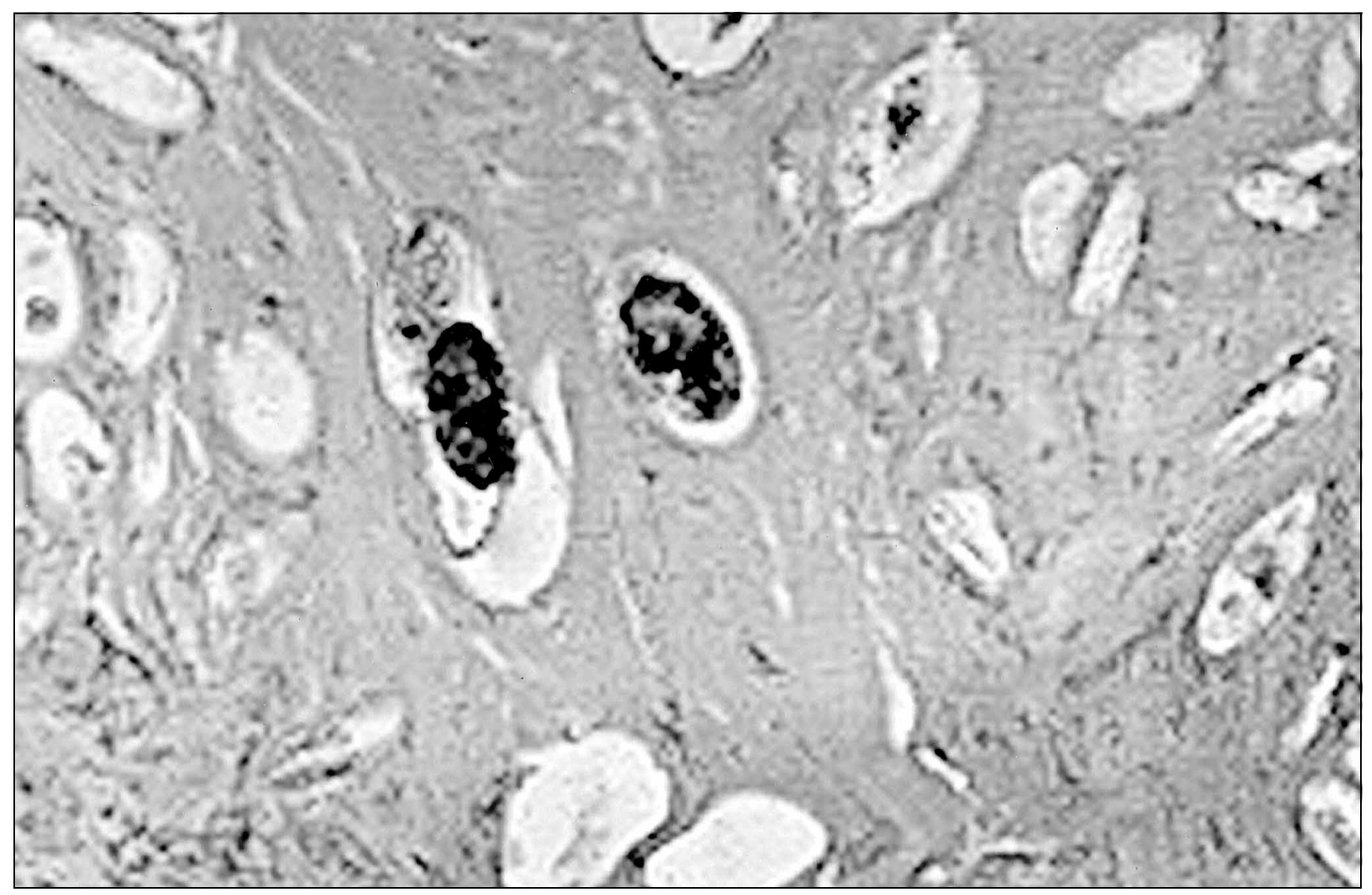

Figure 3. Endoscopic biopsy specimen of a polyp discovered in a patient on routine colonoscopy. Note the Schistosoma japonicum eggs surrounded by fibrous tissue.

lesions called bilharziomas can cause intestinal obstruction [50] or be confused with malignancy [51,52]. Histopathologic examination reveals the characteristic schistosome eggs within the inflammatory mass.

A more common finding in intestinal disease is diffuse polyposis, present in up to $20 \%$ of cases [53]. The polyps are inflammatory in nature (not adenomatous) and can lead to chronic gastrointestinal blood and protein loss. The resultant anemia and hypoalbuminemia are often clinically significant. Treatment with antischistosomal medications can reduce the density and number of polyps [54,55]. Endoscopic polypectomy can be pursued in cases of residual polyps. Elimination of polyps has been shown to dramatically improve anemia and hypoalbuminemia [56].

Fibrotic strictures [57], fistulas [58,59], bowel perforation [60-62], and other consequences of chronic bowel inflammation in schistosomiasis have been reported $[63,64]$ but are less common than polyposis. These disease manifestations usually require surgical treatment, obviously in concert with antischistosomal chemotherapy.

\section{Diagnosis}

For physicians practicing in areas where schistosomiasis is rarely encountered, the key diagnostic hurdle is suspicion of the disease. Schistosomiasis should be considered in the differential diagnosis for patients presenting with any of the aforementioned clinical entities when potential exposure has occurred. A history of contact with fresh water in endemic areas is required, and a recollection of swimmer's itch may provide an important clue to the diagnosis of schistosomiasis.

The traditional diagnosis of schistosomiasis depends on the identification of ova in the stool or urine. The KatoKatz method of preparation is the most widely accepted, using a $25-\mathrm{mg}$ or $50-\mathrm{mg}$ stool sample [65]. Because of the inconstant nature of egg shedding, the sensitivity of a single test is poor. With tests repeated daily for 3 days, sensitivity improves to $90 \%$ [66]. The Kato-Katz method also allows quantification of the egg count per volume of feces, which in turn correlates to worm burden and severity of infection. However, the technique appears to be less sensitive in S. japonicum infection [67]. Also, particularly in lighter infections, it is possible to have multiple negative stool studies in the setting of schistosomiasis. Another means of obtaining eggs is through endoscopic colon or rectal biopsy, which has superior sensitivity compared with stool studies if multiple biopsies are obtained [68].

Serologic study has become useful for diagnosis of schistosomiasis, and both circulating antigen and antibody tests are available. Antibody testing is only marginally useful for residents of schistosomiasis-endemic areas, 


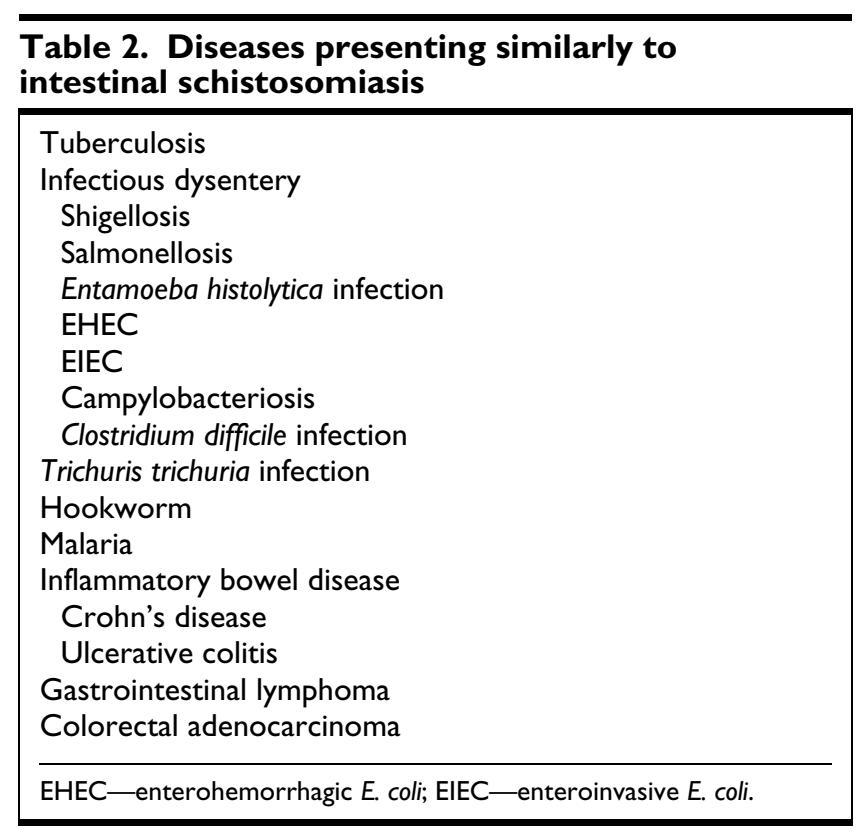

because the antibody persists for years after infection and cannot distinguish between light and heavy infection. However, antibody testing may be used in travelers returning to areas where schistosomiasis is not present, or for hosts that would be expected to have no antibody to Schistosoma antigens.

The antibody tests have shown variable rates of sensitivity and specificity, according to the antigens used, but the commonly used immunofluorescent antibody test (IFAT) has good sensitivity for acute infection in travelers. Currently, the US Centers for Disease Control (CDC) performs a Falcon assay screening test enzymelinked immunoassay (FAST-ELISA) using adult worm antigens, also with excellent sensitivity and specificity in acute infection [69].

Antigen testing, developed over the past several decades, is gaining acceptance as a reliable diagnostic technique for both chronic and acute infections. The most accepted antigen tests are the circulating anodic antigen (CAA) and the circulating cathodic antigen (CCA). These antigens are detectable by ELISA, very stable, genus specific, and correlated to worm burden $[70 \bullet \bullet]$. The sensitivity of these tests in combination is between $65 \%$ and $100 \%$, depending on the burden of infection and thoroughness of the parasitologic evaluation. The test becomes rapidly negative after treatment. The SEA is another useful worm antigen test because egg antigen may persist in the serum for a longer period of time following therapy [71].

\section{Treatment of Infection}

Three drugs are available for treatment of schistosomiasis: praziquantel, oxamniquine, and metrifonate, although metrifonate is no longer manufactured and is difficult to acquire. Praziquantel is the drug of choice for all Schisto- soma species infections, with once-daily dosing. Metrifonate can only be used for $S$. haematobium infections because the response to the other pathogens is not predictable [72].

Praziquantel has rapid activity against adult worms with changes in the tegument and muscular activity, possibly resulting from calcium ion flux within the worm [73]. The drug may cause paralysis of the worm with dislodgment. Also important may be exposure of previously "hidden" worm antigens to which the host might respond. In animal models, hosts depleted of CD4 cells were unable to clear infection when praziquantel was administered, implying that the host response is important to the drug activity [74]. However, the true mechanism of action remains unknown.

The dose of praziquantel for $S$. haematobium and $S$. mansoni infections is generally $40 \mathrm{mg} / \mathrm{kg}$ once daily, and for $S$. japonicum it is $60 \mathrm{mg} / \mathrm{kg} / \mathrm{d}$ usually divided into two doses. The medication is generally well tolerated, with neurologic side effects most common, including dizziness, headache, and malaise occurring in up to $90 \%$ of patients. Gastrointestinal side effects are also very common and include nausea, vomiting, and abdominal discomfort [75].

Oxamniquine is useful for $S$. mansoni infections, although its mode of action is not well understood. There is some evidence that oxamniquine may cause genome damage to the worm, but there is no evidence of mutagenicity to humans [72]. The drug is more effective in South America, the Caribbean, and West Africa than in other areas, such as North Africa, where a much higher dosage may be required. A single dose of $15 \mathrm{mg} / \mathrm{kg} / \mathrm{d}$ is generally used in sensitive strains, with typical neurologic side effects of drowsiness, headache, and dizziness occurring in about $30 \%$ to $50 \%$ of patients [73]. Nausea, orange discoloration of the urine, and occasional fever (possibly caused by host response to release of worm antigen) are also reported [76]. Community treatment with this compound has been well tolerated and effective.

The success of therapy for schistosomiasis seems to be related to the burden of disease, and it is clear that some strains are resistant to chemotherapeutic agents. However, resistance to praziquantel does not seem to confer resistance to oxamniquine, and vice versa. Also, a recent study suggests that resistance to praziquantel does not appear to be rapidly increasing despite widespread control efforts using this drug [77].

\section{Future Research}

Although mass chemotherapy with praziquantel has demonstrated value in control efforts, concern remains that rapid reinfection in areas of high prevalence will require more sustained and durable effects. A vaccine against schistosomiasis has been a focus of research for several decades.

A number of promising vaccine modalities have been explored, including native and recombinant peptide vaccines, DNA vaccines, cytokine-modulating vaccines and irradiated products [78-81]. Six candidate vaccines 
have shown some promise in animal models: Sm28GST (glutathione-S-transferase), Sm97 (paramyosin), IrV-5 (irradiation-associated vaccine antigen), TPI (triosephosphate isomerase), Sm23, and Sm14 (fatty acid binding protein). Any schistosome vaccine faces substantial barriers prior to implementation in humans.

\section{Conclusions}

Schistosomiasis remains an important disease in many parts of the world. With international travel increasing, physicians from all corners of the globe need to keep a high index of suspicion for this parasitic infection. Recognizing and treating the consequences of chronic infection, especially hepatosplenic disease, is crucial.

Developments in immunology and advances in our understanding of the complex inflammatory response to Schistosoma infection demonstrate how much work remains toward development of a vaccine. Parallel work in public health and sanitation, ecology, and pharmacology are needed if there is to be any hope of controlling or eliminating schistosomiasis.

\section{Disclaimer}

The views expressed in this article are those of the authors and do not reflect the official policy or position of the Department of the Navy, the Department of Defense, or the United States Government.

\section{References and Recommended Reading}

Papers of particular interest, published recently, have been highlighted as:

- Of importance

- Of major importance

1. Ruffer MA: Note on the presence of Bilharzia haematobium in Egyptian mummies of the 20th dynasty (1250-1000 BC). BJM 1910, 1:16.

2. Colley DG: Ancient Egypt and today: enough scourges to go around. Emerging Infect Dis 1996, 2:362-363.

3. Kiernan F: The blood fluke that saved Formosa. Harper's, April 1959:45-47.

4. Farley J: Bilharzia: A History of Imperial Tropical Medicine. New York: Cambridge University Press; 1991.

5. Fulford AJC, Butterworth AE, Sturrock RF, Ouma JH: On the use of age-intensity data to detect immunity to parasitic infections with special reference to Schistosoma mansoni in Kenya. Parasitology 1992, 105:219-227.

6. Butterworth AE, Dunne DW, Fulford AJC, et al: Immunity and morbidity in Schistosoma mansoni infection: quantitative aspects. Am J Trop Med Hyg 1996, 55:109-115.

7. Chitsulo L, Engels D, Montresor A, Savioli L: The global status of schistosomiasis and its control. Acta Tropica 2000, 77:41-51.

8. Geboes K, el-Dosoky I, el-Wahab A, Abou Almagd K: The immunopathology of Schistosoma mansoni granulomas in human colonic schistosomiasis. Virchows Arch A Pathol Anat Histopathol 1990, 416:527-534.

9. Fallon PG: Immunopathology of schistosomiasis: a cautionary tale of mice and men. Immunol Today 2000, 21:29-35.
10. Mathew RC, Boros DL: Anti-L3T4 antibody treatment suppresses granuloma formation and abrogates antigen induced interleukin-2 production in Schistosoma mansoni infection. Infect Immun 1986, 54:820-826.

11. Staedecker M: The development of granulomas in schistosomiasis: genetic backgrounds, regulatory pathways, and specific egg antigen responses that influence the magnitude of disease. Microb Infect 1999, 1:505-510.

This concise article summarizes important new developments in the understanding of schistosome-induced granuloma formation.

12. Omer FM, Kurtzhals JA, Riley EM: Maintaining the Immunological balance in parasitic infections: a role for TGF- $\beta$ ? Parasitol Today 2000, 16:18-23.

13.• Dessein AJ, Marquet S, Henri S, et al.: Infection and disease in human schistosomiasis mansoni are under distinct major gene control. Microb Infect 1999, 1:561-567.

This paper summarizes recent important findings suggesting that burden of disease in schistosomiasis may relate to inheritance of genetic region 5q31-33. This region may play a vital role in cytokine regulation and cellular immunity. The findings have significant implications for vaccine development.

14. Colley DG, Garcia AA, Lambertucci JR, et al.: Immune responses during human schistosomiasis. XII. Differential responses in patients with hepatosplenic disease. Am J Trop Med Hyg 1986, 35:793-802.

15. Dunne DW, Butterworth AE, Fulford AJC, et al.: Immunity after treatment of human schistosomiasis: association between IgE antibodies to adult worm antigens and resistance to reinfection. Eur J Immunol 1992, 22:1483-1494.

16. Garcia EG, Mitchell GF, Beall JM, Tiu WU: Schistosoma japonicum: the modulation of lung granuloma and inhibition of egg maturation in mice by human sera. Asian Pac J Allergy Immunol 1985, 3:156-160.

17. Wu CH, Giambrone M, Howard DJ, et al.: The nature of collagen in hepatic fibrosis in murine schistosomiasis. Hepatology 1982, 2:366-371.

18. Souza MRDA, Toledo CFD, Borges DR: Thrombocytopenia as a predictor of portal hypertension in schistosomiasis. Dig Dis Sci 2000, 45:1964-1970.

19. Symmers WC: Note on a new form of liver cirrhosis due to the presence of the ova of Bilharzia haematobia. J Pathol Bacteriol 1904, 9:237-239.

20. Cairo Working Group: The use of diagnostic ultrasound in schistosomiasis: attempts at standardization of methodology. Acta Tropica 1992, 51:45-64.

21. Thomas AK, Dittrich M, Kardorff R, et al.: Evaluation of ultrasonographic staging systems for the assessment of Schistosoma mansoni induced hepatic involvement. Acta Tropica 1997, 68:347-356.

The authors demonstrate the inherent difficulty in getting reliable interobserver accuracy with ultrasound staging systems. Importantly, they propose modifications to improve the utility of ultrasound in evaluating hepatic schistosomiasis. Early lesions remain difficult to evaluate.

22. Pereira LMMB, Domingues ALC, Spinelli V, McFarlane IG: Ultrasonography of the liver and spleen in Brazilian patients with hepatosplenic schistosomiasis and cirrhosis. Am J Trop Med Hyg 1998, 92:639-642.

23. Stone PJ: Potential use of collagen and elastin degradation markers for monitoring liver fibrosis in schistosomiasis. Acta Tropica 2000, 77:97-99.

24. Bica I, Hamer DH, Stadecker MJ: Hepatic schistosomiasis. Infect Dis Clin North Am 2000, 14:583-604.

25. Denie C, Vachiery F, Elman A, et al.: Systemic and splanchnic hemodynamic changes in patients with hepatic schistosomiasis. Liver 1996, 16:309-312.

26. Strickland GT: Gastrointestinal manifestations of schistosomiasis. Gut 1994, 35:1334-1337.

27. Kiire CF: Controlled trial of propranolol to prevent recurrent variceal bleeding in patients with non-cirrhotic portal fibrosis. BMJ 1989, 298:1363-1365. 
28. Pagliaro L, D'Amico G, Sorensen TIA, et al.: Prevention of first bleeding in cirrhosis: a meta-analysis of randomized trials of nonsurgical treatment. Ann Intern Med 1992, 117:59-70.

29. da Silvia Rohr MR, Siqueria ES, Brant CQ, et al.: Prospective study of bacteremia rate after elastic band ligation and sclerotherapy of esophageal varices in patients with hepatosplenic schistosomiasis. Gastrointest Endosc 1997, 46:321-323.

30. Al Karawi MA, El-Sheikh Mohamed AR, Ahmed AMM, Shariq S, Yasawy MI: Longterm outcome of endoscopic sclerotherapy of variceal bleeding: comparitive study between schistosomiasis and others. Hepato-Gastroenterology 1996, 43:287-292.

31. Contractor QQ, Contractor TQ, Kher YR. Sclerotherapy in bleeding gastric varices of hepatic schistosomiasis. If Clin Gastroenterol 1996, 23:97-100.

32. Mostafa I, Omar MM, Nouh A: Endoscopic control of gastric variceal bleeding with butyl cyanoacrylate in patients with schistosomiasis. J Egypt Soc Parasitol 1997, 27:405-410.

This method is promising for the management of variceal bleeding in schistosomiasis. The $7.5 \%$ overall mortality rate (including one treatment-related death) is an impressive result. The results of this small study need to be independently verified.

33. Hassab MA: Non shunt operation in portal hypertension without cirrhosis. Surg Gynecol Obstet 1970, 131:648-654.

34. De Jesus Lopes Filho G, Haddad CM: Late clinical, bioch emical endoscopic and electroencephalographic evaluation of patients with schistosomal portal hypertension treated with distal splenorenal shunt. Int J Surg 1998, 83:42-47.

35. Hassab MA: Gastro-esophageal decongestion and splenectomy GEDS (Hassab) in the management of bleeding varices: review of the literature. Intl Surg 1998, 83:38-41.

36. Elliott DE. Schistosomiasis: pathophysiology, diagnosis and treatment. Gastroenterol Clin North Am 1996, 25:599-625.

37. LaBerge JM, Somberg KA, Lake JR, et al.: Two-year outcome following transjugular intrahepatic portosystemic shunt for variceal bleeding: results in $\mathbf{9 0}$ patients. Gastroenterology 1995, 108:1143-1151.

$38 . \bullet$ Grace ND: Practice guidelines: diagnosis and treatment of gastrointestinal bleeding secondary to portal hypertension. Am J Gastroenterol 1997, 92:1081-1091.

This paper presents the current state of the art for the management of variceal bleeding. Knowledge of this material is crucial for any practitioner who manages this most lethal complication of schistosomiasis. As discussed in the text, these guidelines are applicable to patients with schistosomal induced portal hypertensive bleeding.

39. Abdel-Wahab MF, Zakaria S, Kamel M, et al.: High seroprevalence of hepatitis $\mathrm{C}$ among risk groups in Egypt. Am J Trop Med Hyg 1994, 51:563-567.

40. Darwish MA, Faris R, Clemens JD, et al.: High seroprevalence of hepatitis A, B, C, and E viruses in residents in an Egyptian village in the Nile delta: a pilot study. Am J Trop Med Hyg 1996, 54:554-558.

41. Madwar MA, Tahawy ME, Strickland GT: The relationship between uncomplicated schistosomiasis and hepatitis B infection. Trans R Soc Trop Med Hyg 1989, 83:233-236.

42. Attia MA: Prevalence of hepatitis B and C in Egypt and Africa. Antiviral Ther 1998, 3(suppl 3):1-9.

43.•• Frank C, Mohamed MK, Strickland GT, et al:: The role of parenteral antischistosomal therapy in the spread of hepatitis C virus in Egypt. Lancet 2000, 355:887-891.

This very well-done cohort study presents the most detailed evidence of the relationship between antischistosomal therapy and the spread of hepatitis C.

44. Souto FJ, Fontes CJ, Martelli CM, et al.: Hepatitis C virus prevalence among an immigrant community to the southern Amazon, Brazil. Mem Inst Oswaldo Cruz 1999, 94:719-723.
45. Badawi A, Michael MS: Risk factors for hepatocellular carcinoma in Egypt: the role of hepatitis-B viral infection and schistosomiasis. Anticancer Res 1999, 19:4563-4568.

Hepatocellular carcinoma is a major health problem in Egypt. This evaluation demonstrates the complex interplay of numerous risk factors for the disease. The importance of viral hepatitis and schistosomiasis is noted.

46. Kamal SA, Madwar MA, Peters T, et al.: Interferon therapy in patients with chronic hepatitis $\mathrm{C}$ and schistosomiasis. $J$ Hepatol 2000, 32:172-174.

This small study illustrates the problems encountered in treating patients coinfected with HCV and schistosomiasis. Larger studies and studies of combination therapy need to be done. The timing of antischistosomal therapy relative to anti-HCV therapy also remains to be addressed.

47. Maizels RM, Bundy DA, Selkirk ME, et al.: Immunological modulation and evasion by helminth parasites in human populations. Nature 1993, 365:797-805.

48. Rocha MO, Pedroso ER, Lambertucci JR, et al.: Gastro-intestinal manifestations of the initial phase of schistosomiasis mansoni. Ann Trop Med Parasitol 1995, 89:271-278.

49. Smith JH, Said M, Kelada AS: Studies on schistosomal rectal and colonic polyposis. Am J Trop Med Hyg 1977, 26:80-84.

50. Elmasalme FN, Raheem MA, Badawy A, et al.: Rectosigmoid bilharzioma causing intestinal obstruction. J Pediatr Surg 1997, 32:631-633.

51. Zimbalist E, Gettenberg G, Brejt H: Ileocolonic schistosomiasis presenting as lymphoma. Am J Gastroenterol 1987, 82:476-478.

52. Prosser JM, Kasznica J, Gottlieb LS, Wade G: Bilharzial pseudotumors: dramatic manifestation of schistosomiasis: report of a case. Human Pathol 1994, 25:98-101.

53. Dimmette RM, Sproat AF: Rectosigmoid polyps in schistosomiasis. I. General clinical and pathologic considerations. Am J Trop Med Hyg 1955, 4:1057-1067.

54. Mohamed AR, al Karawi M, Yasawy MI: Schistosomal colonic disease. Gut 1990, 31:439-442.

55. Nebel OT, El Masry NA, Castell DO, et al.: Schistosomal disease of the colon: a reversible form of polyposis. Gastroenterology 1974, 64:939-943.

56. Hussein AM, Medany S, Abou el Magd AM, et al.: Multiple endoscopic polypectomies for schistosomal polyposis of the colon. Lancet 1983, 1:673-674.

57. Wright SG, Renton P, Swarbrick ET: Stricture of the descending colon due to schistosomiasis. Postgrad Med J 1976, 52:601-604.

58. Contractor QQ, Benson L, Schulz TB, et al:: Duodenal involvement in Schistosoma mansoni infection. Gut 1988, 29:1011-1012.

59. Kunin J, Bejar J, Eldar S: Schistosomiasis as a cause of rectovaginal fistula: a brief case report. Isr J Med Sci 1996, 32:1109-1111

60. Atik FA, Lopes Filho GJ, Linhares MdM, et al.: Large intestine obstruction complicated with perforation: a rare manifestation of Schistosoma mansoni infection. Rev Paul Med 1998, 116:1781-1783.

61. Golakai VK, Makunike R: Perforation of terminal ileum and appendix in typhoid enteritis: a report of two cases. East Afr Med J 1997, 74:796-799.

62. Wu TS, Chen TC, Chen RJ, et al:: Schistosoma japonicum infection presenting with colon perforation: case report. Chang Keng I Hsueh 1999, 22:676-681.

63. Abul-Khair MH: Bilhariziasis and prolapse of the rectum. Br J Surg 1976, 63:891-892.

64. Jones HJS, Ibrahim AEK, Deroda J: Schistosomiasis of the appendix in the UK. Br J Clin Pract 1997, 51:183.

65. Katz N, Chaves A, Pellegrino A: A simple device for quantitative stool thick smear technique in schistosomiasis mansoni. Rev Inst Med Trop Sao Paulo 1972, 14:397-400.

66. Engels D, Sinzinkayo E, Gryseels B: Day-to-day egg count fluctuation in Schistosoma mansoni infection and its operational implications. Am J Trop Med Hyg 1996, 54:319. 
67. Olds GR, Olveda R, Wu G, et al.: Immunity and morbidity in schistosomiasis japonicum infection. Am J Trop Med Hyg 1996, 55:121-126.

68. Abdel-Hafez MA, Bolbol AH: Fibre-optic sigmoidoscopy compared with the Kato technique in diagnosis and evaluation of the intensity of Schistosoma mansoni infection. Trans R Soc Trop Med Hyg 1992, 86:641.

69. Tsang VCW, Wilkins PP: Immunodiagnosis of schistosomiasis. Immunol Invest 1997, 26:175-188.

70.• Van Lieshout L, Polderman AM, Deedler AM: Immunodiagnosis by determination of the circulating antigens CAA and CCA, in particular in individuals with recent or light infections. Acta Tropica 2000, 77:69-80.

The authors present data summarizing the utility of a new serum-based test for schistosomiasis. The data also support use of this method for verifying eradication of disease following treatment. The potential advantage of serum testing over stool testing is evident, although the Katz method remains the gold standard for the diagnosis of schistosomiasis. Further evaluation of CAA and CCA may result in this approach becoming the diagnostic method of choice for schistosomiasis.

71. Nibbeling HAM, van Lieshout L, Deedler AM: Levels of circulating soluble egg antigen in urine of individuals infected with Schistosoma mansoni before and after treatment with praziquantel. Trans $R$ Soc Trop Med Hyg 1998, 92:675-677.

72. Cioli D, Pica-Mattoccia L, Archer S: Antischistosomal drugs: past present and future. Pharmacol Ther 1995, 68:35-85.
73. Garcia Goyoco C, Nazario-Lopez H, Ruiz Tiben E, et al.: The efficacy of oxamniquine in acute schistosomiasis. Bol Asoc Med P R 1997, 4:63-69.

74. Sabah AA, Fletcher C, Webbe G, Doenhoff MJ: Schistosoma mansoni: reduced efficacy of chemotherapy in infected T-cell deprived mice. Exper Parasitol 1985, 60:348-354.

75. Saconato H, Atallah A: Interventions for treating schistosomiasis mansoni. Cochrane Database Syst Rev 2000, CD000528.

76. McEvoy GK: AFHS Drug Information. Bethesda, MD: American Society of Health-System Pharmacists; 2000.

77. King $\mathrm{CH}$, Muchiri EM, Ouma JH: Evidence against rapid emergence of praziquantel resistance in Schistosoma haematobium, Kenya. Emerging Infect Dis 2000, 6:585-594.

78. Harn DA, Reynolds SR, Chikunguwo S, et al.: Synthetic peptide vaccines for schistosomiasis. Pharm Biotechnol 1995, 6:891-905.

79. Waine GJ, McManus DP: Schistosomiasis vaccine development: the current picture. Bioessays 1997, 19:435-443.

80. Bergquist NR: Schistosomiasis vaccine development: progress and prospects. Mem Inst Oswaldo Cruzd 1998, 93:95-101.

81. Wilson RA, Coulson PS: Strategies for a schistosome vaccine: can we manipulate the immune response effectively? Microbes Infect 1999, 1:535-543.

82. Melvin DM, Brooke MM, Sadun EH: Common Intestinal Helminths of Man. Life Cycle Charts. Atlanta, GA: Centers for Disease Control; 1964. 